\title{
Mitochondrial DNA-HVR1 Variation Reveals Genetic Heterogeneity in Thai-Isan Peoples from the Lower Region of Northeastern Thailand
}

\author{
Wibhu Kutanan $^{1 *}$, Suparat Srithawong ${ }^{1}$, Artittaya Kamlao ${ }^{2}$, Jatupol Kampuansai ${ }^{3}$ \\ ${ }^{1}$ Department of Biology, Faculty of Science, Khon Kaen University, Khon Kaen, Thailand \\ ${ }^{2}$ Forensic Science Program, Faculty of Science, Khon Kaen University, Khon Kaen, Thailand \\ ${ }^{3}$ Department of Biology, Faculty of Science, Chiang Mai University, Chiang Mai, Thailand \\ Email: "wibhu@kku.ac.th
}

Received November $12^{\text {th }}, 2013$; revised December $15^{\text {th }}, 2013$; accepted January $9^{\text {th }}, 2014$

\begin{abstract}
Copyright (c) 2014 Wibhu Kutanan et al. This is an open access article distributed under the Creative Commons Attribution License, which permits unrestricted use, distribution, and reproduction in any medium, provided the original work is properly cited. In accordance of the Creative Commons Attribution License all Copyrights (C) 2014 are reserved for SCIRP and the owner of the intellectual property Wibhu Kutanan et al. All Copyright (C) 2014 are guarded by law and by SCIRP as a guardian.
\end{abstract}

\begin{abstract}
The Thai-Isan are the largest ethnic group in Northeastern Thailand, who migrated from the territory of present-day Laos around 200 years ago. There are a limited number of previous studies of mtDNA diversity in Northeastern Thai populations. The present study investigates genetic variation and genetic structure in three Thai-Isan populations by analyzing mitochondrial DNA variation in hypervariable region 1 . We also evaluate genetic relationship and admixture between Thai-Isan and surrounding populations from Northeastern Thailand, and neighboring countries. The studied Thai-Isan populations reveal genetic differentiation from each other and from compared populations. Thai-Isan exhibit a close relationship with surrounding populations, particularly the Lao and Khmer, reflecting extensive gene flow among them. Admixture proportions observed in most Thai-Isan populations exhibit a higher contribution from the parental Lao than the Khmer. Different admixture patterns reflect genetic heterogeneity of Thai-Isan groups. The lower the latitude, the higher the Khmer contribution might be associated with the ethnic constitution of parental populations in each Thai-Isan population. More genetic data from HVR2 and coding regions, as well as different marker systems are needed to infer population history of Thai-Isan populations.
\end{abstract}

Keywords: mtDNA Diversity; Genetic Relationship; Genetic Admixture; Thai-Isan; Northeastern Thailand

\section{Introduction}

Isan is the term employed by Thais referring to the region and people of Northeastern Thailand. Northeastern Thailand geographically shares a border with Laos and Cambodia, and lies in close proximity to Vietnam, thus, this region has substantial cultural, linguistic, and ethnic diversity. The word "Isan" is derived from Isana which is the Sanskrit name of the ancient Mon-Khmer kingdom (Bonnie Pacala \& Somroay, 2010). The Thai-Isan people refer to the predominant ethnic peoples who are ethnically Lao but have Thai citizenship. The population of Northeastern Thailand also comprises native Mon-Khmer speaking groups, e.g. Khmer and Chaobon, and other Taispeaking groups such as the Phuthai (Keyes, 1974; Lewis, 2009). Hence, there are approximately eighteen ethnicities, three major languages and twenty-two dialects in Northeastern Thailand (Premsrirat, 1999). Among several ethnic affiliations, the majority of these populations are Thai-Isan people (over 20 million inhabitants) whose regional identity is completely associated with the Lao language (McCargo \& Hongladarom, 2004).

\footnotetext{
*Corresponding author.
}

The historical motherland of Thai-Isan peoples is in the area of the present-day Lao People's Democratic Republic (LPRD). The Isan and LPRD are geographically and politically divided by the Mekong River. Around the $9^{\text {th }}$ century, before the immigration from Laos, Northeastern Thailand was heavily influenced by the Khmer empire in Angkor which raised several remarkable Khmer temples and relics, especially in southern Isan (Wongtaed, 1999; Schliesinger, 2001). After the decline of the Khmer empire, a large Lao population was forcibly relocated to the area of Isan between the mid-fourteenth and the late-eighteenth centuries (Keyes, 1967). When the French entered Indochina in the late $19^{\text {th }}$ century, the Mekong was used as a boundary between Lao people. Isan became the region on the southern bank of the Mekong River, controlled by the state of Siam, while the area on the north side (present-day LPRD) was controlled by the French (Schliesinger, 2001).

According to the historical records, biculturalism comprising the Khmer and Thai-Isan populations existed in the lower part of Isan, particularly spanning the provinces of Surin, Buriram, Ubon-Ratchathani, Nakorn Ratchasima and Srisaket (Vail, 2007). Therefore, this region is of great interest to scholars studying linguistics (Smalley, 1988; Smalley, 1994), culture, 
history (Wyatt, 1984; Khanittanan, 2001), archaeology (Welch, 1998; Talbot \& Janthed, 2002), and politics (Wyatt, 1969; McCargo \& Hongladarom, 2001). However, few studies of anthropological genetics in the southern part of Northeastern Thailand have ever been published.

In recent years, mitochondrial DNA (mtDNA) variation has been proven to be the most powerful genetic marker for investigating gene pools and tracing maternal genetic relatedness (Cavalli-Sforza \& Feldman, 2003; Malyarchuk et al., 2008). In Thailand, several studies of human genetic structure and variation to infer population history and migratory routes were exclusively focused in the Northern part of Thailand, while in Isan, one of the most ethnicly diverse parts of Thailand, a limited number of such studies were reported. Only Fucharoen et al. (2001), Lertrit et al. (2008), and Boonsoda et al. (2013) revealed genetic data for four populations, namely the Phutai, Chaobon, Thai Khon Kaen, Thai Korat, and Khmer by studying mtDNA variation. Therefore, the present study analyses mtDNA variation to reveal population affinity and admixture between the Thai-Isan from the lower part of Northern Thailand and surrounding populations reported in previous literatures.

\section{Materials and Methods}

\section{Sample Collection and DNA Extraction}

After interviewing for linguistic and personal history as well as obtaining consent from all volunteers, buccal swabs were collected from 134 unrelated Thai-Isan individuals belonging to three populations from Buriram Province (Isan- $\mathrm{Bu}, \mathrm{n}=51$ ), Ubon-Ratchathani Province (Isan-Ub, $n=45$ ) and Chaiyabhum Province (Isan-Ch, $\mathrm{n}=38$ ). These provinces are located in the lower part of Northeastern Thailand. The Khon Kaen University ethics committee for human research approved the research protocol. Genomic DNA was extracted according to the manufacturer's instructions (Puregene DNA Buccal Cell Kit, Qiagen). Data of mtDNA variability of HVR-1 from surrounding populations from Northeastern Thailand (Isan-Kr, Isan-Kk, Khmer1, Phutai, and Chaobon) as well as populations in neighboring countries (Laos, Khmer2, Khmer3, Cham, and Kinh) from previous literature (Table 1 and Figure 1) were obtained in order to compare population affinity admixture analyses.

\section{mtDNA Amplification and Sequencing}

The mtDNA control region was amplified by a published primer pair as described elsewhere (Schurr et al., 1999). PCR products were sent for purification and the hypervariable region 1 (HVR1) was sequenced by Macrogen (Seoul, Korea). Sequencing reactions were performed using a published set of primers (Kampuansai et al., 2007). The sequencing results were edited, assembled and aligned with the revised Cambridge Reference Sequence (Andrews et al., 1999) using SeqScape software v.2.0 (Applied Biosystem, Foster City, CA). The mtDNA

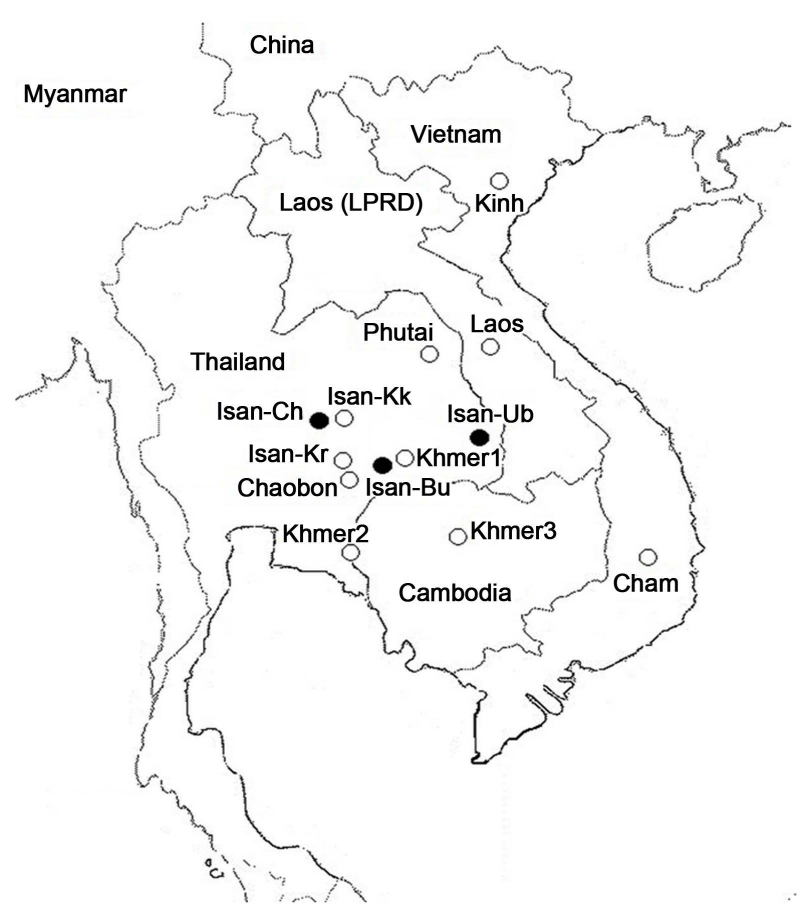

Figure 1.

Geographic distribution of the studied Thai-Isan populations from the Northeastern Thailand $(\bullet)$ and surrounding compared populations $(\mathrm{O})$ from Thailand and neighboring countries.

Table 1.

General information and genetic diversities of the studied Thai-Isan and compared populations.

\begin{tabular}{ccccccc}
\hline Population & $\begin{array}{c}\text { Sample } \\
\text { size }\end{array}$ & $\begin{array}{c}\text { Language family, } \\
\text { subfamily }\end{array}$ & $\begin{array}{c}\text { Location } \\
\text { (province, country) }\end{array}$ & Reference & $\begin{array}{c}\text { Haplotype diversity } \\
\text { (S.E.) }\end{array}$ & $\begin{array}{c}\text { Nucleotide diversity } \\
\text { (S.E.) }\end{array}$ \\
\hline Isan-Bu & 51 & TK, TT & Buriram, Thailand & Present study & $0.9718(0.0109)$ & $0.0232(0.0122)$ \\
Isan-Ub & 45 & TK, TT & Ubon Ratchathani, Thailand & Present study & $0.9323(0.0283)$ & $0.0225(0.0119)$ \\
Isan-Ch & 38 & TK, TT & Chaiyabhum, Thailand & Present study & $0.9673(0.0172)$ & $0.0216(0.0115)$ \\
Isan-Kk & 44 & TK, TT & Khon Kaen, Thailand & Fuchareon et al. (2001) & $0.9989(0.0051)$ & $0.0211(0.0112)$ \\
Isan-Kr & 32 & TK, TT & Nakorn Ratchasima, Thailand & Lertrit et al. (2008) & $1.0000(0.0078)$ & $0.0210(0.0112)$ \\
Phutai & 25 & TK, TT & Mukdahan, Thailand & Fuchareon et al. (2001) & $0.9767(0.0193)$ & $0.0227(0.0122)$ \\
Laos & 213 & TK, TT & LPRD & Bodner et al. (2011) & $0.9918(0.0019)$ & $0.0210(0.0109)$ \\
Chaobon & 20 & AA, MK & Nakorn Ratchasima, Thailand & Lertrit et al. (2007) & $0.9474(0.0300)$ & $0.0221(0.0120)$ \\
Khmer1 & 36 & AA, MK & Surin, Thailand & Boonsoda et al. (2013) & $0.9317(0.0324)$ & $0.0199(0.0106)$ \\
Khmer2 & 22 & AA, MK & Thailand-Cambodia border & Lertrit et al. (2007) & $0.9913(0.0165)$ & $0.0169(0.0093)$ \\
Khmer3 & 31 & AA, MK & Cambodia & Black et al. (2006) & $0.9527(0.0261)$ & $0.0223(0.0118)$ \\
Kinh & 138 & AA, MK & Vietnam & Peng et al. (2010) & $0.9912(0.0030)$ & $0.0235(0.0121)$ \\
Cham & 167 & AS, MP & Vietnam & Peng et al. (2010) & $0.9878(0.0027)$ & $0.0253(0.0130)$ \\
\hline
\end{tabular}

åLanguage: TK: Tai-Kadai, AA: Austro-asiatic, AS: Austronesian, TT: Tai, MK: Mon-Khmer, MP: Malayo-Polynesian. 
sequences can be obtained from the corresponding author on request.

\section{Statistical Analyses}

The mtDNA sequences of 336 nucleotides (np 16048-16383) were identified for polymorphic sites by DnaSP v.5.10 (Librado \& Rozas, 2009). Arlequin 3.5 program (Excoffier \& Lischer, 2010) was used to calculate intrapopulation diversity: nucleotide diversity $(\pi)$, number of haplotype, haplotype diversity $(h)$, and mean number of pairwise differences (MPD). Several parameters describing demographic history were observed by mismatch distribution and neutrality approaches. DnaSP v.5.10 software was also employed to construct the observed pairwise differences against the expected mismatch distribution under both constant size population and sudden population expansion models. A raggedness index value ( $r$ ) (Harpending, 1994), neutrality estimators, Fu's Fs (Fu, 1997) and Tajima’s D (Tajima, 1989) data were calculated using Arlequin 3.5 program. In order to evaluate population relationships, the same program was employed to compute genetic distance based on pairwise difference $\left(F_{s t}\right)$ and then a genetic distance matrix was plotted in two dimensions by means of multidimensional scaling (MDS) using the commercially available STATISTICA 7.0 (StatSoft Software Ltd.). Admixture estimation was performed by ADMIX 2.0 (Dupanloup \& Bertorelle, 2001), taking mutation and molecular divergence between alleles into account (Bertorelle \& Excoffier, 1998; Dupanloup \& Bertorelle, 2001).

\section{Result and Discussion}

Genetic Variation and Population Expansion of the Studied Thai-Isan Populations

A 336 bp mtDNA-HVR1 segment between positions 16048 to 16383 was sequenced and compared among three studied populations. Within 134 samples, 76 different haplotypes were identified and defined by 92 variable positions, (Figure 2). Among 76 haplotypes, 53 and 15 were single unique and multiple unique, respectively, while only 8 shared haplotypes were found. Among the 8 shared haplotype, only one haplotype (16129-16192-16223-16297) was present in all populations. This indicates that the studied populations were differentiated. The highest frequency of haplotype was 16093-16124-1614816223 , which is exclusively found in the Isan-Ub populations. The number of intrapopulation MPD were 7.5657 (Isan-Ub),

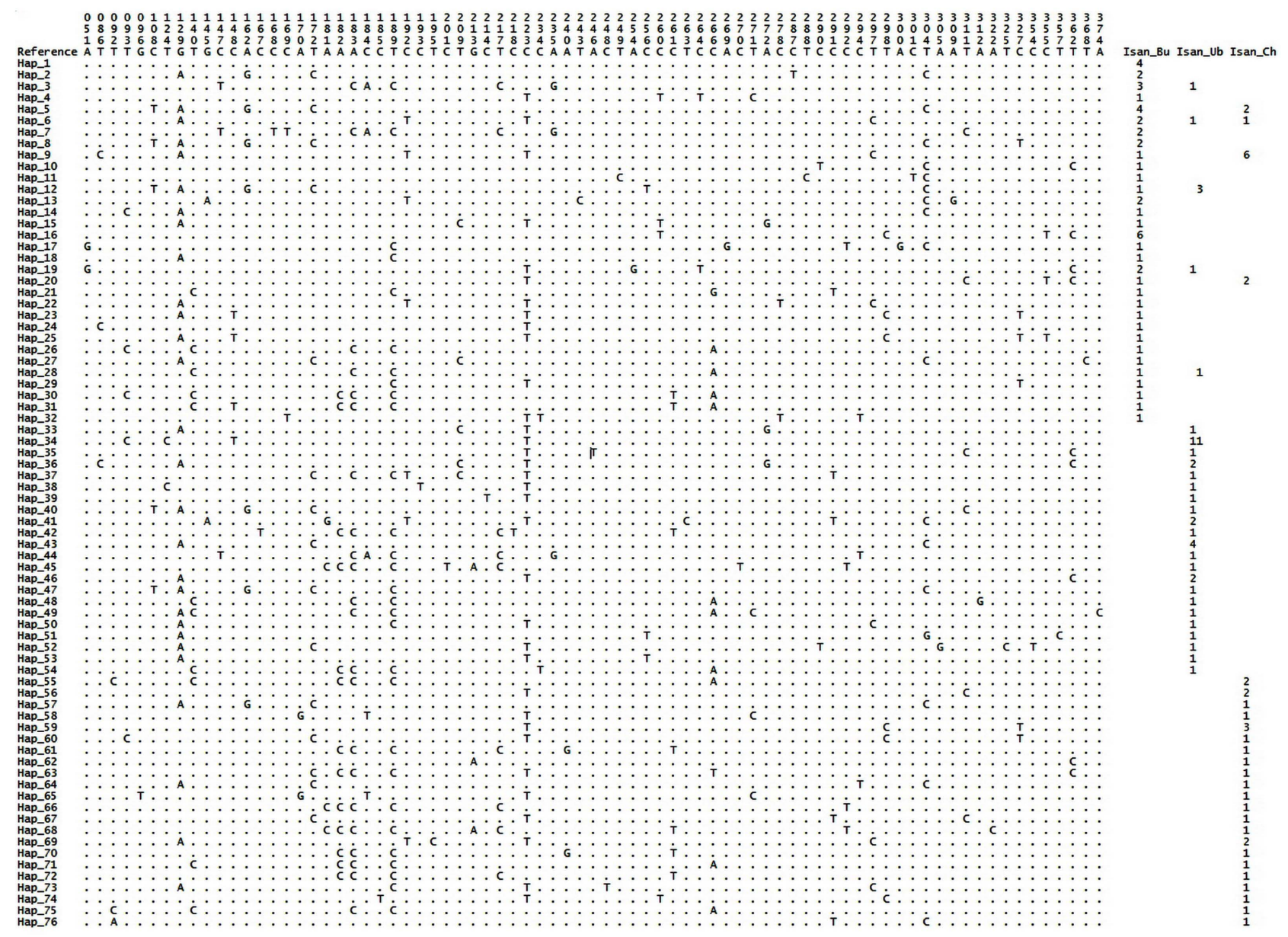

Figure 2.

Nucleotide differences in the 76 distinct haplotypes, defined by 92 polymorphic sites are shown based on a comparison with the 336-bp Revised Cambridge Reference Sequence ranged from 16,024 - 16,383. The reference is presented below the order for polymorphic sites (16+). For the other 76 haplotypes, only differences from the Revised Cambridge Reference Sequence are indicated. The number of individuals which are found in each haplotype is embedded in Arabic numerals on the right. 
7.8086 (Isan-Bu), and 7.2660 (Isan-Ch), reflected higher genetic heterogeneity within Isan-Bu than Isan-Ub and Isan-Ch. The interpopulation MPD, ranged from 7.6749 to 7.9394 , were relatively high compared to previous report (Bodner et al., 2011) reflecting genetic differentiation among them. Genetic structure among the populations was tested for significant variation by AMOVA (Excoffier et al., 1992). Most genetic variation was the difference within populations (96.83\%), whereas the rest of the variance $(3.17 \%)$ was found among populations. The AMOVA result was significant $\left(F_{s t}=0.0316 ; P=0.0000\right)$, indicating a genetic difference among Thai-Isan populations. Pairwise genetic distances with significant levels $(P<0.05)$ were 0.0317 (Isan-Bu and Isan-Ub), 0.0298 (Isan-Bu and Isan-Ch), and 0.0336 (Isan-Ub and Isan-Ch), reflecting genetic differentiation among present Thai-Isan populations.

Although population growth was not the primary subject of this study, we performed Fu's Fs and Tajima's D to explore the demographic history of each population. These two parameters were used to evaluate neutrality under the null hypothesis, which stated that if the studied populations evolve with a constant effective population size, all mutations are selectively neutral. The value of the Fu's Fs in Isan-Bu, Isan-Ub, and IsanCh was $-14.22887(P=0.0000),-9.64724(P=0.0080)$, and $-11.4357(P=0.0000)$, respectively. For the D test of Tajima, non-significant negative values were detected (Isan-Bu = -1.48827 ( $P=0.057)$, Isan-Ub $=-1.33313(P=0.093)$, Isan$\mathrm{Ch}=-0.69434(P=0.256)$. The highly significant negative Fu's Fs and negative Tajima's D, implied a recent bottleneck following an expansion in the population. Another demographic parameter showed the lower raggedness index (less than 0.03) as well as the unimodal mismatch distribution graph for these populations (data not shown), providing congruent evidence for population growth and expansion (Rogers \& Harpending, 1992).

\section{Genetic Comparison with Surrounding Populations}

Two parameters used for estimating the genetic diversity within Isan populations were haplotype diversity and nucleotide diversity. The highest haplotype diversity (1.0000) was found in Isan-Kr, the lowest in Khmer1 (0.9317), reflecting a weaker degree of diversity in Khmer1. Studied Thai-Isan populations showed relatively high haplotype diversity ( $h=$ from 0.9323 to 0.9718). Nucleotide diversity in studied Thai-Isan populations $(\pi)$ ranged from 0.0216 to 0.0232 , similar to compared populations (Table 1).

To shed more light on genetic structure, the interpopulation MPD which ranged from 6.7128 (Isan-Kk-Khmer2) to 9.3 (Khmer1-Chaobon), while the corrected MPD values ranged from 0 (Laos-Kinh) to 1.9401 (Khmer1-Chaobon), indicating genetic similarity between Laos and Kinh. Khmer1 and Chaobon had high MPD values comparing to all other populations, indicating differences in genetic structure of these two populations to others. In pairwise $F_{s t}$ analysis among 78 comparisons, 61 (78\%) were statistically significant $(P<0.05)$ (data not shown). Intermediate to high $F_{s t}$ values with significant levels pointed out genetic differentiation among populations. The Khmer1, Chaobon, and Cham had significant $F_{\text {st }}$ values for all comparisons. The Isan-Kr, Khmer2 and Phutai had the top three non-significant pairwise $F_{s t}$ values, indicating extensive gene flow within these populations.

There was mostly a significant pairwise $F_{s t}$ between the stu- died Thai-Isan populations and other compared populations, supporting genetic differentiation of Thai-Isan populations. MDS analysis based on the $F_{\text {st }}$ matrix was performed to infer population affinity (Figure 3). The MDS reveal that Isan-Bu, Isan-Kk, and Isan-Kr were clustered with the Laos, Kinh, Cham, Phutai, and Khmer2 around the axis center, showing a genetic similarity. The Isan-Ub, Isan-Ch, Cham, and Khmer3 appear more distant from the center of the axis, indicating some degree of differentiation. Although Chaobon and Khmer1 were geographically closer to all Thai-Isan populations, they were separated from the cluster at the axis center, reflecting a great genetic distinction in both populations, which concordant to interpopulation MPD result. Interestingly, the three Khmer groups were genetically different. The Khmer1 from Surin Province had greater differentiation, which could be possibly explained by a weakly haplotype diversity as well as a low intrapopulation MPD, indicating a loss in genetic diversity (Hurles et al., 2002; Davis et al., 2011) due to a possible drift effect. In Surin, Buriram, Srisaket, and Ubon Rachathani Provinces, several Khmer stone sanctuaries and architectural sites were found, indicating strong Khmer influence since at least the time of Khmer empire (Schliesinger, 2000). Vail (2007) stated that there are over a million speakers of Khmer language in this region, making it probably the largest non-Tai language speaking group within the borders of the Thai state. Therefore, extensive gene flow might be observed in genetic analysis, reflected in the Khmer2. The Khmer2 is intermediately positioned between the Khmer3 from Cambodia and other Taispeaking group. This result suggests genetic exchanges between the Khmers and Thais, conforming to Lertrit et al. (2008) who is the owner of Khmer2 data.

\section{Genetic Admixture}

In admixture analysis, two population groups were defined, the admixed ones and the parental populations. All Thai-Isan populations were considered as admixed populations who received genetic elements from their putative parental sources. Although in the current study eight neighboring populations were employed to compare genetic relationships, based on historical evidence, only three ethnic affiliations belonging to the Khmer (Khmer1, Khmer2, and Khmer3), Chaobon, and Lao

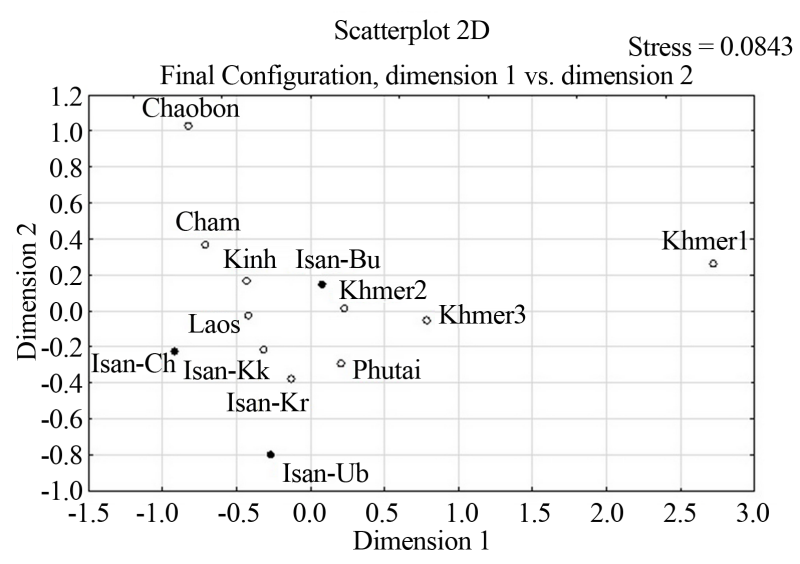

Figure 3.

Multidimensional scaling scatter plot of studied populations based on pairwise difference $(F s t)$. $(\bullet$ the present study's Thai-Isan populations, O surrounding compared populations). 
were regarded as parental populations in admixture analysis. In brief, the Khmer and Chaobon who speak Mon-Khmer were the native inhabitants in lower Northeastern Thailand before the Tai-speaking immigrants migrated en mass from Laos as a result of political conflicts within Laos around 600 years ago (Schliesinger, 2000; Schliesinger, 2001).

Admixture proportions reveal that the contributions of the Lao maternal gene pool in the extant Thai-Isan populations were varied, as shown in Figure 4. Admixture results indicated genetic heterogeneity within Thai-Isan populations. Except for Isan- $\mathrm{Bu}$, other Thai-Isan populations received more genetic contributions from the parental Lao (47\% to 94\%) than the parental Khmer ( $0 \%$ to $31 \%$ ) and Chaobon (3\% to $13 \%$ ). When considering the Khmer contribution, the lower the latitude, the higher the Khmer contribution was observed. The Khmer made the highest contribution in the Isan-Bu, which was in agreement with linguistic, historical, and archaeological evidence. Two hypotheses describe the origin of Isan-Bu. First, the Isan-Bu might be immigrants from Laos and after their migration they were mixed with the native Khmer in present day Buriram Province. The second hypothesis proposes that after the forcible movement of the Lao people, the native Khmers in Buriram adopted the Lao culture and language (Vail, 2006).

The highest Chaobon influences were found in Isan-Kr and Isan-Ub. As earlier described in Lertrit et al. (2008) who studied the ethnography of Chaobon, the Chaobon were found only in Thailand and scattered among different villages in the areas of Nakorn Ratchasima, Chaiyabhum, and Petchaboon Provinces. Because of shared geographic location in Nakorn Ratchasima Province between Chaobon and Isan-Kr, albeit limited by cultural difference, gene flow might explain the slight genetic contribution from parental sources to an admixed one. In addition, the Chaobon's contribution to Isan-Ub from Ubon Rachathani Province is questionable because no evidence indicated the existence of Chaobon in Ubon Ratchathani. It might suggest that this fraction derived from other native Mon-Khmer inhabitants in Ubon Ratchathani who shared ancestors with the Chaobon, like the Bru and the Suay.

In the area of Chaiyabhum Province, both Tai-Kadai speaking people and Chaobon were inhabitants, therefore, our expectation was a relative Chaobon contribution to the Isan-Ch maternal gene pool, but the data rejected our prediction. Only a

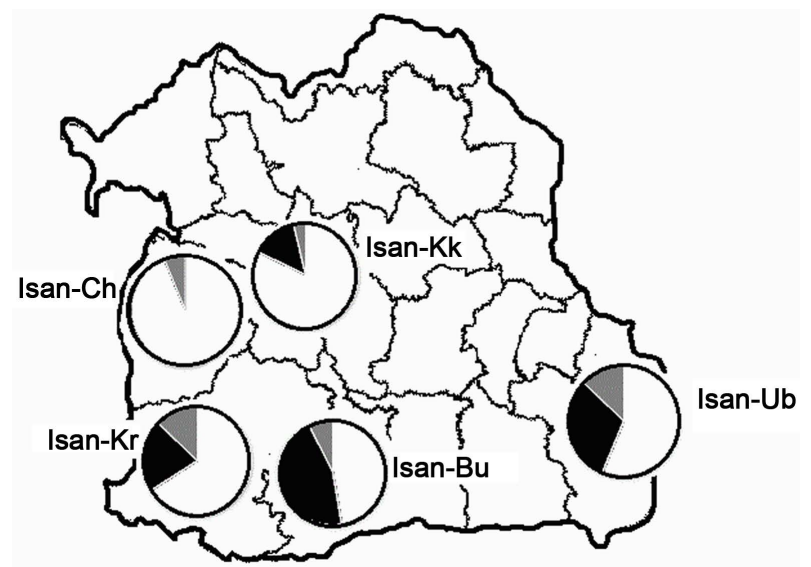

Figure 4.

Pie diagrams showing the distribution of Laos (white), Khmer (black) and Chaobon (grey) contributing to the Thai-Isan populations. few Chaobon fractions (6.2\%) were found. This suggests that Chaobon in Chaiyabhum and Nakorn Ratchasima provinces were genetically different groups, thus, in the future more genetic data from Chaobon in Chaiyabhum will be useful to evaluate the complete genetic structure in Thai-Isan populations. Moreover, no Khmer influence was detected in Isan-Ch. Most of the genetic composition within Isan-Ch is contributed by the Laos parental source.

However, it should be cautioned that the Lao samples in LPRD from Bodner et al. (2011) which were used as parental populations were multi-ethnic in origin and from across the country, and there is no data of ethnic or linguistic affiliation of each sample. Because of an extensively ethnic diversity as described in Bodner et al. (2011), the contribution from parental Lao in LPRD to the admixed Thai-Isan populations might not be purely from the Tai-Kadai speaking Lao, but the MonKhmer and Hmong-Mien Laos could also be the sources.

\section{Conclusion}

The current study based on mitochondrial DNA variation in HVR1 regions of Thai-Isan populations from the lower part of Northeastern Thailand shows high levels of genetic diversity and differentiation. The significant difference among Thai-Isan populations might be shaped by different levels of admixture from putative distinct parental populations. The estimation of admixture suggests that Thai-Isan populations were genetically influenced by parental Lao and Khmer populations. This result shows that Thai-Isan people from Northeastern Thailand and Lao people from the LPDR previously had genetic similarity, but after the mass migration period, the people from Laos were mixed with the Khmer and vice versa. The possible promotion of speedy admixture between two linguistically and culturally different ethnicities was the process of "Thaification", which is the policy that was proposed by the Thai government in the $20^{\text {th }}$ century for the purpose of de-emphasizing the Laos and Khmer origins of people in Northeastern Thailand (Winichakul, 2000). After that time, all people in this region began referring to themselves as "Thai-Isan". Therefore, either the Thaification process, geographic proximity or both factors are important in determining genetic structure of the current Thai-Isan populations as well as the native Khmer. Heterogeneity of admixture patterns might be associated with the ethnic constitution of parental populations in each area. To shed more light on admixture analysis, more genetic information of various ethnic affiliations in Northeastern Thailand as well as the Laos samples descended from Laos Lan Xang is required. Since this study solely examines mitochondrial DNA in HVR1 region, a larger reading frame such as HVR2 and coding region, as well as paternal markers is needed to help understand the complex migration and population history of Thai-Isan populations.

\section{Acknowledgements}

The authors wish to thank all volunteers and village chiefs for their participation in sample collections. We also thank Dr. Alvin Yoshinaga for valuable comments and suggestions on the manuscript. This research was funded by Khon Kaen University, Thailand (Grant No. 563802).

\section{Declaration of Interest}

The authors report no declarations of interest. 


\section{REFERENCES}

Andrews, R. M., Kubacka, I., Chinnery, P. F., Lightowlers, R. N., Turnbull, D. M., \& Howell, N. (1999). Reanalysis and revision of the Cambridge reference sequence for human mitochondrial DNA. $\mathrm{Na}$ ture Genetics, 23, 147. http://dx.doi.org/10.1038/7727

Bertorelle, G., \& Excoffier, L. (1998). Inferring admixture proportions from molecular data. Molecular Biology and Evolution, 15, 12981311. http://dx.doi.org/10.1093/oxfordjournals.molbev.a025858

Black, M. L., Dufall, K., Wise, C., Sullivan, S., \& Bittles, A. H. (2006). Genetic ancestries in northwest Cambodia. Annals of Human Biology, 33, 620-627. http://dx.doi.org/10.1080/03014460600882561

Bodner, M., Zimmermann, B., Röck, A., Kloss-Brandstätter, A., Horst, D., Horst, B., Sengchanh, S., Sanguansermsri, T., Horst, J., Krämer, T., Schneider, P. M., \& Parson, W. (2011). Southeast Asian diversity: First insights into the complex mtDNA structure of Laos. BMC Evolutionary Biology, 11, 49. http://dx.doi.org/10.1186/1471-2148-11-49

Bonnie Pacala, B., \& Somroay, Y. (2010). Buddhist murals of northeast Thailand: Reflection of the Isan heartland. Chiangmai: Silkworm Books.

Boonsoda, P., Srithawong, S., Srikuka, S., \& Kutanan, W. (2013). Mitochondrial DNA variation of the Khmer in Surin Province, Thailand. Thai Journal of Genetics, 6, 40-48.

Cavalli-Sforza, L. L., \& Feldman M. W. (2003). The application of molecular genetic approaches to the study of human evolution. $\mathrm{Na}$ ture Genetics, 33, 266-275. http://dx.doi.org/10.1038/ng1113

Davis, M. C., Novak, S. J., \& Hampikian, G. (2011). Mitochondrial DNA Analysis of an immigrant Basque population: Loss of diversity due to founder effects. American Journal of Physical Anthropology, 144, 516-525. http://dx.doi.org/10.1002/ajpa.21432

Dupanloup, I., \& Bertorelle, G. (2001). Inferring admixture proportions from molecular data: Extension to any number of parental populations. Molecular Biology and Evolution, 18, 672-675. http://dx.doi.org/10.1093/oxfordjournals.molbev.a003847

Excoffier, L., \& Lischer, H. E. L. (2010). Arlequin suite ver 3.5: A new series of programs to perform population genetics analyses under Linux and Windows. Molecular Ecology Resources, 10, 564-567. http://dx.doi.org/10.1111/j.1755-0998.2010.02847.x

Excoffier, L., Smouse, P., \& Wuattro, J. (1992). Analysis of molecular variance inferred from metric distance among DNA haplotypes: Application to human mitochondrial DNA restriction data. Genetics, 131, 479-491.

Fu, Y. X. (1997). Statistical tests of neutrality of mutations against population growth, hitchhiking and background selection. Genetics, 147, 915-925.

Fucharoen, G., Fucharoen, S., \& Horai, S. (2001). Mitochondrial DNA polymorphisms in Thailand. Journal of Human Genetics, 46, 115125. http://dx.doi.org/10.1007/s100380170098

Harpending, H. C. (1994). Signature of ancient population growth in a low-resolution mitochondrial DNA mismatch distribution. Human Biology, 66, 591-600.

Hurles, M. E., Nicholson, J., Bosch, E., Renfrew, C., Sykes, B. C., \& Jobling, M. A. (2002). Y chromosomal evidence for the origins of Oceanic-speaking peoples. Genetics, 160, 289-303.

Kampuansai, J., Bertorelle, G., Castri, L., Nakbunlung, S., Seielstad, M., \& Kangwanpong, D. (2007). Mitochondrial DNA variation of Tai speaking peoples in northern Thailand. Science Asia, 33, 443-448. http://dx.doi.org/10.2306/scienceasia1513-1874.2007.33.443

Keyes, C. (1967) Isan: Regionalism in northeastern Thailand. New York: Department of Asian Studies, Southeast Asia Program, Cornell University.

Keyes, C. (1974). A note on the ancient towns and cities of northeastern Thailand. Southeast Asian Studies, 11, 497-506.

Khanittanan, W. (2001). Khmero-Thai: The great change in the history of Thai language in the Chao Praya basin. Journal of Language and Linguistics, 19, 35-50.

Lertrit, P., Poolsuwan, S., Thosarat, R., Sanpachudayan, T., Boonyarit, H., Chinpaisal, C., \& Suktitipat, B. (2008). Genetic history of southeast Asian populations as revealed by ancient and modern human mitochondrial DNA analysis. American Journal of Physical Anthropology, 137, 425-440. http://dx.doi.org/10.1002/ajpa.20884

Lewis, M. P. (2009). Ethnologue: Languages of the world (16th ed.). Dallas: SIL International. http://www.ethnologue.com/

Librado, P., \& Rozas, J. (2009) DnaSP v5: A software for comprehensive analysis of DNA polymorphism data. Bioinformatics, 25, 14511452. http://dx.doi.org/10.1093/bioinformatics/btp187

Malyarchuk, B. A., Perkova, M. A., Derenko, M. V., Vanecek, T., Lazur, J., \& Gomolcak, P. (2008). Mitochondrial DNA variability in Slovaks, with application to the Roma origin. Annals of Human Genetics, 72, 228-240. http://dx.doi.org/10.1111/j.1469-1809.2007.00410.x

McCargo, D., \& Hongladarom, K. (2004). Contesting Isan-ness: Discourses of Politics and Identity in Northeast Thailand. Asian Ethnicity, 5, 220-234. http://dx.doi.org/10.1080/1463136042000221898

Peng, M. S., Quang, H. H., Dang, K. P., Trieu, A. V., Wang, H. W., Yao, Y. G., Kong, Q. P., \& Zhang, Y. P. (2010). Tracing the Austronesian footprint in mainland southeast Asia: A perspective from mitochondrial DNA. Molecular Biology and Evolution, 27, $2417-$ 2430. http://dx.doi.org/10.1093/molbev/msq131

Premsrirat, S. (1999). Language and ethnicity on Khorat Plateau. In The Princess Maha Chakri Sirindhorn Anthropology Centre, Thailand: Culture and Society (pp. 267-284). Bangkok: Ruen Kaew Printing.

Rogers, A. R., \& Harpending, H. (1992). Population growth makes waves in the distribution of pairwise genetic differences. Molecular Biology and Evolution, 9, 552-569.

Schliesinger, J. (2000). Ethnic groups of Thailand: Non-Tai-speaking peoples. Bangkok: White Lotus Press.

Schliesinger, J. (2001). Tai Group of Thailand, Volume 1: Introduction and overview. Bangkok: White Lotus Press.

Schurr, T. G., Sukernik, R. I., Starikovskaya, Y. B., \& Wallace, D. C. (1999). Mitochondrial DNA variation in Koryaks and Itel'men: Population replacement in the Okhotsk sea-Bering sea region during the Neolithic. American Journal of Physical Anthropology, 108, 1-39. http://dx.doi.org/10.1002/(SICI)1096-8644(199901)108:1<1::AID-A JPA1>3.0.CO;2-1

Smalley, W. A. (1988). Multilingualism in the Northern Khmer population of Thailand. Language Sciences, 10, 395-408. http://dx.doi.org/10.1016/0388-0001(88)90023-X

Smalley, W. A. (1994). Linguistic diversity and national unity: Language ecology in Thailand. Chicago: University of Chicago Press.

Tajima, F. (1989). Statistical method for testing the neutral mutation hypothesis by DNA polymorphism. Genetics, 123, 585-595.

Talbot, S., \& Janthed, C. (2002). Northeast Thailand before Angkor: Evidence from an Archaeological Excavation at the Prasat Hin Phimai. Asia Perspectives, 40, 179-194. http://dx.doi.org/10.1353/asi.2001.0027

Vail, P. (2006). Can a language of a million speakers be endangered? Language shift and apathy among northern Khmer speakers in Thailand. International Journal of the Sociology of Language, 178, 135-147.

Vail, P. (2007). Thailand's Khmer as “invisible minority”: Language, ethnicity and cultural politics in north-eastern Thailand. Asian Ethnicity, 8, 111-130. http://dx.doi.org/10.1080/14631360701406247

Welch, D. J. (1998). Archaeology of northeast Thailand in relation to the pre-Khmer and Khmer historical records. International Journal of Historical Archaeology, 2, 205-233. http://dx.doi.org/10.1023/A:1027320309113

Winichakul, T. (2000). The quest for "Siwilai”: A geographical discourse of civilizational thinking in the late nineteenth and early twentieth-century Siam. The Journal of Asian Studies, 59, 528-549.

Wongtaed, S. (1999). Explore Isan society and cultures. Bangkok: Art and culture Press.

Wyatt, D. K. (1969). The politics of reform in Thailand. New Haven: Yale University Press.

Wyatt, D. K. (1984). Thailand: A short history. New Haven: Yale University Press. 